Sultan Qaboos University Journal of Arts \& Social Science
جامعة السلطان قابوس الإداب مجلة الآداب والعلوم الاجتماعية

OMANI PARENTS' BELIEFS ABOUT THEIR COMPETNCE IN DEALING WITH THEIR ADOLESCENT CHILDREN'S BEHAVIORAL PROBLEMS

Fayez A. Simadi

Associate Professor

Department of Sociology and Social Work

College of Arts \& Social Science

Sultan Qaboos University

smadi.fayez@yahoo.com 


\title{
OMANI PARENTS' BELIEFS ABOUT THEIR COMPETNCE IN DEALING WITH THEIR ADOLESCENT CHILDREN'S BEHAVIORAL PROBLEMS
}

\author{
Fayez A. Simadi
}

\section{Abstract:}

This study examines the effect of some demographic variables such as educational achievement, income, residence, profession and gender on parents' beliefs about their competence to deal with their adolescent children's behavioral problems. The adolescent behavioral problems investigated in this study include failure in school, alcoholism and addiction to drugs. A group of 350 parents of adolescent children was randomly selected from several districts in the Governorate of Muscat in the Sultanate of Oman. The researcher developed a questionnaire to measure the impact of these variables on certain behavioral problems specifically identified for the study. ANOVA was used to examine the role of socio-demographic variables in explaining parents' beliefs about their competence to prevent such problems. Results reveal a positive impact for the variables: educational achievement, occupation, family income, gender, and place of residence. To investigate the effects of these sociodemographic factors on each of the dimensions of competence, MANOVA was used. Results show that there is a direct relationship between the variable of level of income and children's failure in school, and that the variable of gender and the problem of alcoholism and drug addiction are related. Finally, the variable of place of residence is related to the problems of alcoholism, addiction to drugs and school failure. These results were discussed in light of findings of similar previous studies and within the framework of the Omani social lifestyles.

Key Words: Parental competence, adolescents, behavioral problems.

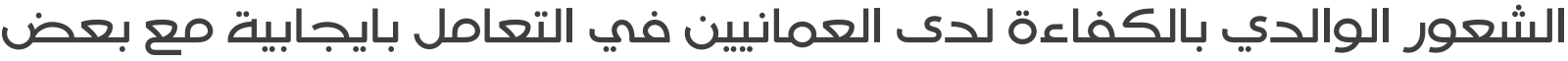 المشكلات السلوكية لدى أبنائهم المراهين}

\section{فايز الصمادي}

جاءت هذه الدراسة لتدرس مدى تأثير بعض المتغيرات الديموغرافية مثل: التحصيل العلمي، مقدار الدخل،مكان الاقامة، المهنة،

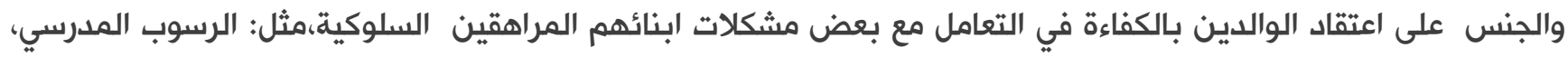

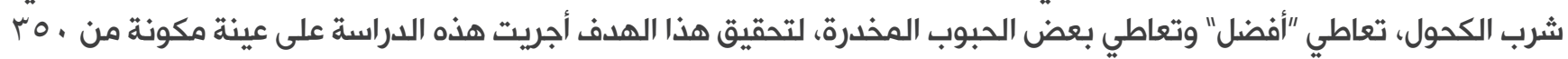

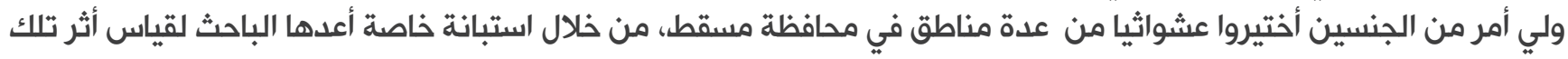

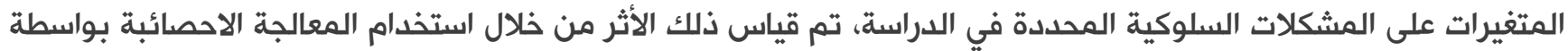

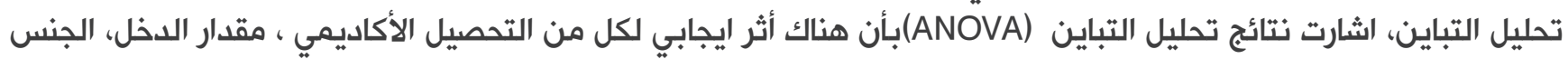

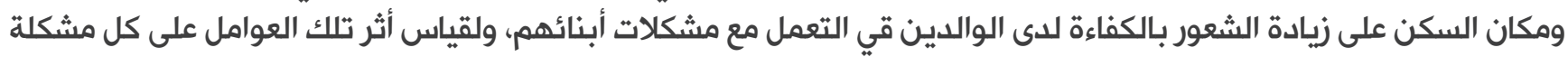

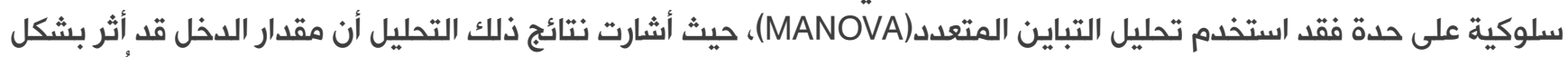

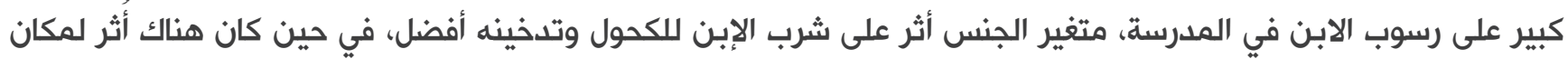

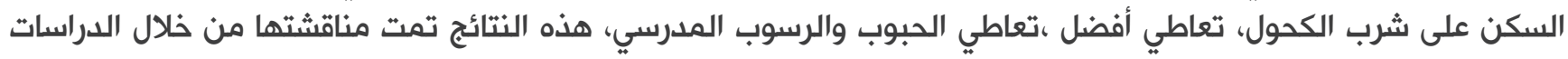




\section{INTRODUCTION}

Adolescence is a stage of transition in which children become adults. There are both biological and psychological changes. The biological changes are accompanied by physical growth spurts, a change in bodily proportions, and the attainment of sexual maturity. These changes contribute in important ways to social and economic changes from dependence on one's family to legal and moral independence. However, there are also a number of psychological changes, such as progressive maturity of sexual attitudes and behaviors that allow adolescents to acquire new social skills helping them to become well-adapted adults. Spirito, Stark, Gil, and Tyc (1995: 310), examined some adolescents' problems, the results of this study indicated that the following problems were significant: drinking alcohol, missing school, getting involved in smoking marijuana, selling drugs, and theft. Since this is so, parents of adolescents have to be active and positive (belief in competency) in dealing with such problems.

Moving from characteristics of parent-adolescent interaction to parental characteristics, it seems that a high level of adolescent antisocial behavior is related to parental feelings of incompetence. These parental characteristics could be viewed as nonspecific indicators of (dysfunction).These nonspecific indicators of psychopathology appear to be better predictors of family functioning than diagnostic categories (Dickstein, Seifer, Hayden, et al., 1998: 23-40).

Both the parent and the adolescent are part of a larger whole, the family, and their interactive relationship takes place within a context of other family relationships. Consistent with the results of previous studies (Gorman-Smith et al., 1996: 115 129), it was found that the degree of emotional involvement of all family members is predictive of adolescent behavior, such as overt conflict between parents to which children are exposed, might be more relevant for child adaptation.

\section{Parents' Beliefs Competency}

Parental competencies have a significant impact on child development. The concept of parental competency involves functional and dysfunctional rearing behavior as well as evaluation of parental coping with challenging rearing situations and self-efficacy of rearing. Enhancing parental education is an important challenge on the background of high prevalence rates of child behavior problems (Gilmore \& Cuskelly, 2008: 48).

Other researchers define parental competence as directly related to parenting skills without reference to who makes the evaluation of ability. For example, Rhoades \& O'Leary (2007: 46) define parental competence as 'parenting behaviors, skills and plans that have been considered to promote positive and adaptive child development outcomes'. Sanders, MarkieDadds and Turner (2003: 21) view parental competence as strongly linked to self-regulation, the central skill in parental ability, which allows parents to: select targets, control their own and their child's behavior, implement strategies and evaluate the effectiveness of their parenting behaviors. Sabatelli and Waldron (1995: 978) argue however, that parental competence has both sides: objective in that it involves an evaluation of whether parenting behaviors are consistent with societal norms and expectations. At this level, the evaluation of competence is made by external sources (e.g. other family members, social workers, child protection officers, community nurses). Parental competence can sometimes be subjective and this is when referring to the parent's assessment of how well 
they perform within their parenting role relative to their expectations. In this situation 'competent parents are those who favorably evaluate their role performance'.

Parental competence is also an attributed status which relies as much on the evaluations of health and social care professionals and the courts as on the behaviour of parents. Evaluations, and preevaluations, of the quality of parenting draw on ideas present in the wider society. These ideas are often not made explicit. Arney, Rogers, Baghurst, Sawyer, \& Prior (2008: 44-52), in their study of parents with learning difficulties revealed that their problems often reflected those of parents of the same social and economic status, and many of their difficulties should be understood as resulting from poverty. This research found that problems were often magnified by the services ostensibly provided for the support of the families, snap evaluations were made, and there was often a failure to involve people in decisions affecting them.

In addition to that, some of the reasons why people need help with parenting relate to anger. In these cases projection is exerted from outside the family in order to protect the child from harm. In other words, help is imposed rather than requested. Principles have been established so that in particular cases, protection can be safe for a child even if the parents' wishes have to be overridden. For example, a shifting from parental rights to the concept of parental responsibility.

Causes for parents needing extra help do not always fit into one neat explanation, as you may have already discovered for yourself. Rather, there are different levels of parental difficulty which overlap. Furthermore, identifying reasons does not automatically mean that solutions can be either achieved or provided. It is beyond the ability of most people to change structural issues, in particular. We might speculate that the difficulty of addressing structural issues is one reason why practitioners and policy makers sometimes limit themselves to approaches which assume that the 'solution' lies at the personal level.

In short, parents' beliefs in their own competency are generally defined as the parents' ability to perceive, interpret accurately, and to respond promptly and appropriately to their children's and adolescents' problems (Nicholls \& Kirkland, 1996: 556). As most studies have been concerned with mothers, further research is needed to understand the dynamics of mothers' and fathers' beliefs in their competency as parents. Contextual factors include parents' family income, level of education, occupations, and place of living, all of which can be termed socioeconomic factors. Demographic characteristics such as gender and socioeconomic factors (SE) influence the onset and severity of various adolescence disorders and also of emotional problems (Angold \& Costello, 1993: 1785). Two global indicators of family functioning (SE factors and family composition) were unrelated to adolescent antisocial behavior. These two indicators were also related to other indicators of family functioning. The significant associations might be because of the wide range of these two indicators.

\section{Socio-demographic Factors}

SE factors have been recognized by several authors as taking an important role in parental behaviors (e.g., Floyd \& Saitzyk, 1992: 607-631; Gerson, 1993: 81). Findings of previous studies led us to expect a positive association between SE indicators and parental competency. Pinderhughes, Dodge, Bates, Pettit, and Zelli (2000: 380-405) found differences between a positive parenting type in which the parent believes that he/she has a significant effect on the outcomes 
of the child (high competency); and the negative parenting type in which the parent believes that he/she has insignificant effect on outcomes of the child (low competency). Parents who believed they had high competency endorsed love, affection, and being a model as critical influences, whereas parents low in competency, especially fathers, tended to endorse aggression and punishment. These competency states are affected by parents' socioeconomic status; e.g. improving of income, education, and occupation can lead to an increase in the competency perception of parents.

Occupation has been found to be positively associated with perceived personal competency for both male and female heads of households (Andrisani, 1977: 319; Downey \& Moen, 1987: 332). Additionally, workers who have been laid off, have had their job status downgraded, or who lose a job due to injury, suffer a decreased sense of competency and an increased sense of powerlessness and psychological distress (Gecas, Seff, \& Ray, 1988: 15; Pearlin, Menaghan, Lieberman, \& Mullan, 1981: 336-357).

\section{Parent's gender}

Pelchata, Boise, and Suaci $(2003,752-757)$ found that mothers are more sensitive, responsive, and involved with their children than fathers. For instance, the interaction style of fathers has been reported to be faster paced, with less verbalizations and more interference with the child's ongoing activities and, more generally, less finely tuned to the child's cues and level of understanding than is that of mothers (McCollum, 1988: 235: Power, 1985:1517). Yet, in contrast to these results, in some well-conducted studies no difference in parents' beliefs in their competency between mothers and fathers has been found (Burchfield-Child, 1986: 128).

\section{TheArabFamilyandParentalcompetency}

Beliefs of competency among Arab parents may be related to the traditional type of family socialization processes (authoritarian style) through the Arab culture. The leader of Arab family is extremely a dominant, high demanding, full of feelings of superiority, and suppressive of others especially children (Wrikat \& Simadi, 2001: 43). However, the modern Arab family has become more open and flexible with children (Wrikat \& Simadi, 2003: 44). These orientations are affected by parents' socio-demographic factors such as the education level, income, occupational status, and quality of life (Simadi, Fatayer, \& Athamneh, 2003: 480). In the present study, I tested the impact of some socio-demographic factors on the parents' beliefs of their competency to prevent some adolescent behavior problems. The results of the study may provide important data that will help us to understand and identify the most influential socio-demographic factors in the socialization processes.

In the present study, I specifically tried to answer the following questions:

1. What is the relationship between the problems experienced by adolescents and the beliefs of the parents of those adolescents about their competency in preventing the problems?

2. What are the effects of socio-demographic factors on the parents' beliefs in their competency concerning the prevention of their adolescents' behavior problems?

3. Are there any differences in the parent belief competency dimensions which could be attributed to differences in their sociodemographic characteristics?

\section{METHOD \\ The Participants}

The participants in the study were selected from 8 
preparatory public schools from Muscat territory in Oman (5 for males and 3 for females). These schools were selected using the clustering sample method using the school as a unit. Then the 10th grade classes were selected randomly from these schools using the section as a unit. About 400 students enrolled in these classes were given a questionnaire to be filled in by their parents, and 350 parents (179 mothers and 171 fathers) returned their completed questionnaires, giving us a response rate of $83 \%$ which was considered to be sufficient for the purpose of the study.

Instrument

To assess the parents' perception of competency in preventing adolescents' problems, the researcher developed a Likert-type scale $(1=$ little effect, 2 = moderate effect, and 3 = strong effect), based on previous research (Spoth \& Conroy, 1993). This instrument has 6 domains representing adolescents' problems, which are: drinking alcohol, taking of Afdal (kind of drug addiction), school failure, teenagers' destroying things, and peer-group troubles. Parents' scores on the questionnaire can range from 5 to 15 . These dimensions have been chosen based on asking some schools' social workers and principals, about the most important problems they face with adolescents in their schools. Thus, the researcher formulated several items to measure these problems as the instrument of study. Validity of the instrument was confirmed using a panel of 10 measurement experts in the fields of sociology, psychology, and education via the content validity method, whereby they were asked to assess the representation of the items as to the concept of parents' competency. Reliability was calculated using Cronbach's alpha which was .84, and was, therefore, considered acceptable. The instrument had clear instructions for parents on how to answer each question.

\section{RESULTS}

The mean score for the sample was $8.80, \mathrm{SD}$ 3.03 (total score), which indicates a fair level of parents' belief in their competency, and does not suggest the presence of a noticeable degree of difficulty in parents' belief in their competency in preventing their adolescents' problems. The sample indicated that they have relatively higher competency in preventing destroying, peer group troubles and failure in school than other problems (Alcohol and taking afdal).The mean score of each item were calculated and shown below in table 1 .

To investigate the effect of socio-demographic factors on parents' belief in their competency, analysis of variance (ANOVA) was used. The results using ANOVA (Table 2) showed that family income had significant effect on the parents' belief in competency $F(2,123)=7.986, p<000$. The occupation of parents also had an effect $F(2,123)$ $=5.005, p<01$. Gender, place of living, and

\begin{tabular}{|l|l|l|l|}
\hline & Domain & Mean & St. Deviations \\
\hline $1-$ & Drinking Alcohol & 1.33 & 0.62 \\
\hline $2-$ & Afdal Taking & 1.29 & 0.61 \\
\hline $3-$ & School failure & 1.69 & 0.70 \\
\hline $4-$ & Peer group troubles & 1.94 & 0.69 \\
\hline $5-$ & Destroy things & 1.99 & 0.71 \\
\hline $6-$ & Total & 8.80 & 3.08 \\
\hline
\end{tabular}

Table 1

The means and standard deviations of the test domains 
education of parents also had a significant effect on their belief in their competency. For gender, the result was $F(1,123)=3.229$, $p<0.05$, the place of living result was $F(1,123)=20.55 p<$ 0.01 , and the education result was $F(2,123)=$ 4.22, $\mathrm{p}<0.05$.

The results also showed that there was no significant effect for the interaction between parents' socio-demographic factors and their belief in their competency, with the exception of the interaction between the parent's occupation and place of living $F(1,123)=4.57, p<0.05$, and the interaction between income, gender, and place of living $F(2,123)=6.35, p<0.01$. However, the main effect (grouped sociodemographic factors) had a strong significant effect on parents' belief in their competency $F(1,1230=833.85, p<0.01$.

Using post hoc comparison (Newman-Kuels) tests between means revealed a significant difference between fathers ( $M=8.34$ ) and mothers, where mothers had a higher belief in their competency than did fathers $(M=11.7)$. There was also a significant difference between urban ( $M=12.66)$ and rural parents, urbanized parents had a greater belief in their competency than did the rural parents ( $M=8.07$ ). There were also significant differences between the results for those with a low level of education and parents who had a mid-level of education ( $M=3.37)$, and between parents with the lowest level of education and the highest level $(M=4.56)$. There was also a

\begin{tabular}{|c|c|c|c|c|}
\hline Source of variance & $S S$ & $D f$ & $F$ & Sig. of $F$ \\
\hline Main effect & 4276.89 & 1 & 833.85 & 0.000 \\
\hline Income & 2124.241 & 2 & 7.986 & 0.000 \\
\hline Occupation & 1336.505 & 2 & 5.005 & 0.007 \\
\hline Gender & 1293.287 & 1 & 3.229 & 0.022 \\
\hline Place of living & 115.91 & 1 & 20.55 & 0.000 \\
\hline Education & 49.30 & 2 & 4.22 & 0.002 \\
\hline Income X Occupation & 25.28 & 4 & 1.21 & 0.271 \\
\hline Income X Gender & 2.22 & 2 & 0.229 & 0.251 \\
\hline Occupation X Gender & 7.62 & 2 & 0.82 & 0.501 \\
\hline Income X Occupation X Gender & 4.52 & 3 & 0.37 & 0.887 \\
\hline Income X P. of Living & 14.16 & 2 & 1.47 & 0.311 \\
\hline Occupation X P. of Living & 23.12 & 1 & 4.57 & 0.050 \\
\hline Gender X P. of Living & 14.22 & 1 & 2.69 & 0.121 \\
\hline Income X Gender X P. of Living & 67.13 & 2 & 6.35 & 0.003 \\
\hline Occupation X Gender X P. of Livin & Income X 4.29 & 1 & 0.91 & 0.390 \\
\hline Income X Education & 31.54 & 4 & 1.65 & 0.240 \\
\hline Occupation X Education & 28.19 & 3 & 2.00 & 0.100 \\
\hline Income X Occupation X Education & 4.35 & 2 & 0.51 & 0.715 \\
\hline Gender X Education & 3.89 & 2 & 0.39 & 0.733 \\
\hline Income X Education X Gender & 32.45 & 4 & 1.81 & 0.265 \\
\hline Occupation X Gender X Education & 0.27 & 1 & 0.045 & 0.915 \\
\hline P. of Living X Education & 2.69 & 1 & 0.46 & 0.541 \\
\hline Income X P. of Living X Education & 13.55 & 2 & 1.74 & 0.411 \\
\hline Gender X P. of Living X Education & 5.98 & 1 & 1.87 & 0.331 \\
\hline Residual & 630.88 & 123 & & \\
\hline
\end{tabular}

Table 2

Summary of ANOVA for effectsof sociodemoggraphic factors on parents' belief in their competencyy 
significant difference between results for parents with a mid-level of education and those with a low level $(M=1.19)$. All these comparisons indicate that better educated parents have a greater belief in their competency than do less well-educated parents. The interactions between other variables were very weak (SS and $\mathrm{F}$ tests $=$ $0)$.

To address the effect of socio-demographic factors on each dimension of parent's competency, MANOVA was used (table3). The results of MANOVA showed that income variation has a significant effect on preventing failure in school $F=3.129, P<0.05)$; the occupation of parents has a significant effect on prevention of destroying things dimension $(\mathrm{F}=3.23, \mathrm{P}<0.05)$ while the parent gender has a significant effect on the dimension of alcohol consumption $F=10.568$, $\mathrm{P}<0.01$ and cigarettes. Afdal prevention $\mathrm{F}=7.973$, $\mathrm{P}<0.01$; the residence has an effect on all the dimensions. Its effect on preventing alcoholism was $(F=11.381, P<0.0$, the effect on preventing of afdal was $(\mathrm{F}=6.795 \mathrm{P}<0.01$; the effect on preventing failure in school was $\mathrm{F}=3.660 \mathrm{P}<0.01$, the effect of bad friends was $F=13.118 P<0.01$, and the effect on preventing teen's destroying things was $F=11.490 P<0.01$; while the education variable has no significant effect on any of the competency variables as shown in table 2.

A comparison test (Newman-Kuels) has to address the effect of the study's variables as independent on each dimension of competency separately. A comparison test (Newman-Kuels) revealed that the parent with the highest level of family income has more competency to prevent school failure $(M=1.80)$ than that with the lowest. Also, it showed that mid-level of parents' occupations have more competency on preventing teens' destroying things $(M=1.33)$ than the lowest level $(M=1.15)$ and the highest level of occupation has more competency than the mid-level $(M=1.73)$.

A summary of means revealed that mothers have more competency $(M=1.46)$ in preventing drinking alcohol than fathers $(M=1.18)$, $(M=1.46)$ as well as preventing afdal taking than fathers $(M=1,11)$. The summary of means indicate that place of residence has affected all the dimensions of competency; urban residents have more competency in all dimensions than rural residents. Urban families' competency in preventing alcohol drinking $(M=1.96)$ was more

\begin{tabular}{|l|l|l|l|l|l|}
\hline \multicolumn{1}{|c|}{ SE } & Drinking Alcohol & Afdal Taking & Failure in School & Peer Pressure & Destroy things \\
\hline Income & 0.276 & 0.260 & $3.129^{*}$ & 2.393 & 2.61 \\
\hline Occupation & 0.187 & 0.426 & 0.026 & 2.643 & 3.23 \\
\hline Gender & $10.568^{* *}$ & $7.973^{* *}$ & 0.400 & 1.391 & 0.354 \\
\hline Place of Living & $11.381^{* *}$ & $6.795^{* *}$ & $3.660^{*}$ & 13.118 & 1.49 \\
\hline Education & 2.248 & 2.591 & 1.332 & 1.416 & 0.229 \\
\hline
\end{tabular}

Table 3

Summary of MANOVA to Dimensions of Parent's Competency and Socio-Demographic Factors

* $\quad \mathrm{P}<0.05$

** $\quad P<0.01$ 
than rural families $(M=1.21)$, Urban families competency on preventing drug use $(M=2.33)$ also, was more than rural families $(M=1.38)$, the urban families tend to have more competency on preventing afdal taking $(M=1.38)$, urban families too $(M=1.20)$. Moreover, people living in the city have more competency in preventing failure in school $(M=2.18)$ than villagers $(M=1.48)$, people living in the cities have more competency in preventing their kids' involvement with bad friends $(M=2.25)$ than villagers $(M=1.40)$. Finally, urban parents have more competency in preventing teens' destroying things $(M=2.11)$ than rural parents $(M=1.37)$, while, the education variable has not affected any of the dependent variables.

\section{DISCUSSION}

With regard to the first question we set out to answer in this study, it is clear that parents rated their perceived competency around the mean (8.80), which means that the parents had a moderate level of belief in their competency in preventing problems in adolescents' behaviors. With regard to our second question, results were consistent with expectations and with the findings of Spoth and Conroy (1993: 230). The gender of the parent in the household showed an inverse relationship with perceived parent competency. Mothers had experienced a higher level of perceived competency than had fathers. This result can be explained as Omani mothers are more participatory and involved with their children than are fathers and they have more time to care for their children than do the fathers. Fathers in Oman usually have to spend longer hours working outside the home, and sometimes even working outside the country (Simadi et al., 2003: 482).

All of the socio-demographic variables included in this study, such as place of living, exhibited the widest range of effects influencing perceived parental competency. The relationship between place of living and perceived parental competency found in this study is consistent with the literature, in that urban people generally have higher levels of perceived parental competency than do rural or village-dwelling parents. It is possible that urban parents have better access to resources (e.g., drug abuse prevention programs, awareness raised by media) which would diminish the perceived likelihood of future adolescent problem behavior (Wrikat \& Simadi, 2001: 44).

As expected, parents' education was significantly and strongly associated with both mothers' and fathers' perception of competency. Parents with more education are more sensitive and efficacious in dealing with their children than are parents with less education. This finding is in accord with the results of many studies (i.e., Floyd \& Saitzyk, 1992: 620; Onufrak, Saylor, Taylor, Eyberg, \& Boyce 1995: 590) about the influence of socioeconomic factors on parental practices. Kohn (1977: 71) proposed that those in higher social positions are more likely to value selfdirection, self-control, and responsibility in their children. Such values and attitudes could well explain the relationship between SE factors and parental sensitivity and competency. It can also be argued that parents who have more education have more resources to help them cope with the stress of rearing a child. They also probably have more opportunities to attend classes on child rearing and have better advice available.

The family income was found to have a significant effect on perceived parental competency. This effect may be due to the level of income of the sample, which was quite adequate level of income for Omani society. This meant that all the parents in our sample had good access to resources for acquiring competency such as media and governmental prevention programs 
that could help them to develop their capability in preventing adolescents' problems (Simadi et al., 2003: 470). Occupation had also effect on parents' perceived competency. This result was expected by the researcher and mirrored with the literature. However, this result may be due to the measure used in the study, which was a very sensitive measure of occupation structure in some countries like Oman (Simadi, 2006: 175). Consistent with the literature, the effects of sociodemographic factors were varied (question 3) on each dimension of perceived competency for parents (e.g. Gekas 1989: 43; Floyd and Saitzyk, 1992: 607-631; Garson, 1993: 71-74). The strongest variable was the place of living; it affected all the dimensions. Gender has affected perceiving drinking alcohol and cigarettes smoking, while occupation and income have affected one variable: perceiving teens' destroying things and failing academically. These results support the previous results in the literature; urban parents have better means of aid to raise their kids, mothers have better chances to know what their kids are doing, especially smoking and drinking alcohol, while parents have less chances to hear about their kids in the working place than at home. The parents who have higher income are usually able to treat the kids' school failure than those who have a lower income. Finally, inconsistent with the literature, parents' level of education did not affect any of the dimensions, previons repated ersults. Thus, regardless of the level of education, the division of labor within the family is still traditionally-based. 


\section{References}

Andrisani, P. J. , 1977, Internal, external attitudes, personal initiative, and the labor market experience of black and white men. Journal of Human Resources, 12(1) 308-328.

Angold, A., \& Costello, E. J. ,1993, Depressive comorbidity in children and adolescents: Empirical theoretical and methodological issues. American Journal of Psychiatry, 150(5) 1779-179 1.

Arney, F., Rogers, H., Baghurst, P., Sawyer, M. \& Prior, M. ,2008, The reliability and validity of the parenting scale for Australian mothers of pre-school aged children. Australian Journal of Psychology, 60, 44-52. Burchfield-Child, S. ,1986, Parents as teachers: Comparisons of mothers and fathers. Infant Behaviors and Development, 9(1), 127-131.

Dickstein, S., Seifer, R., Hayden, L.C., Schiller, M., Sameroff, A.J., Keitner, G., Miller, I. , Rasmussen, S., Matzko, M., \& Magee, K.D. ,1998, Levels of family assessment: II. Impact of maternal psychopathology on family functioning. Journal of Family Psychology, 12: 23-40

Downey, G., \& Moen, P. ,1987, Personal competency, income, and family transitions: A longitudinal study of women heading households Journal of Health and Social Behavior, 28(1), 320-331.

Floyd, F. J., \& Saitzyk, A. R. , 1992, Social class and parenting children with mild and moderate mental retardation. Journal of Paediatric Psychology, 17(2), 607-631.

Gecas, V., Seff, M. A., \& Ray, M. P. ,1988, Injury and depression: The mediating effects of self-concept. Paper presented at the Pacific Sociological Association Meeting, Las Vegas.

Gerson, K. ,1993, No man's land: Men's changing commitments to family and work. New York: Basic Books.

Gilmore, L., \& Cuskelly, M. ,2008, Factor structure of the parenting senseof competence scale using a normative sample. Child: Care, Health \& Development, 35, 48-55.

Gorman-Smith, D., Tolan, P.H., Zelli, A., \& Huesmann, L.R. ,1996, The relation of family functioning to destroy things among inner-city minority youth. Journal of Family Psychology , 10: 115-129.

Kohn, M. L. ,1977, Class and conformity: A study in values (2nd ed.). Chicago: University of Chicago Press.

McCollum, J. A. ,1988, Parent playfulness: A case study of infant twins with handicaps. Child: Care, Health and Development, 14(1), 235-253.

Nicholls, A., \& Kirkland, J. ,1996, Maternal sensitivity: A review of attachment literature definitions. Early Child Development and Care, 120(2), 55-65.

Onufrak, B., Saylor, C. F., Taylor, M. J., Eyberg, S. M. \& Boyce, G. C. , 1995, Determinants of responsiveness in mothers of children with intraventricular hemorrhage. Journal of Paediatric Psychology, 20(5), 587599.

Pearlin, L. I., Menaghan, E. G., Lieberman, M. A., \& Mullan, J. T. ,1981, The stress process. Journal of Health and Social Behavior, 22(4) 337-356.

Pelchata, A., boise F. \& Suaci M. ,2003, Mothers' sensitivity and their children. Journal of Family and Psychology, 17(1), 750-772.

Pinderhughes, E. E., Dodge, A. K., Bates, J. E., Pettit, G. S., \& Zelli, A. ,2000, Discipline responses: Influences of parents' socioeconomic status, ethnicity, beliefs about parenting, stress and cognitive minimal processes. Journal of Family and Psychology, 14(3), 380-405. 
Pleck, J. H. ,1997, Parental involvement: Levels, sources, and consequences. In M. E. Lamb (Ed.), The role of the father in child development (pp. 66- 103). New York: Wiley.

Power, T. G. ,1985, Mother- and father-infant play: A developmental analysis. Child Development, 56(1), 1514-1524.

Power, T. G., \& Parke, R. D. ,1983, Patterns of mother and father play with their 8-month-old infant: A multiple analyses approach. Infant Behavior and Development, 6(2), 453-459.

Rhoades, K.A. \& O'Leary, S. G. ,2007, Factor structure and validity of the Parenting Scale. Journal of Clinical Child and Adolescent Psychology, 36, 137-46.

Sabatelli, R. M. \& Waldron, R. J. ,1995, Measurement issues in the assessment of the experiences of parenthood. Journal of Marriage and the Family, 57, 969-80.

Sanders, M. R., Markie-Dadds, C. \& Turner, K. M. T. ,2003, Theoretical, scientific and clinical foundations of the Triple P - Positive Parenting Program: a population approach to the promotion of parenting competence. Parenting Research and Practice Monograph, 1, 1-21.

Sanders, M. R. \& Woolley, M. L. ,2005, The relationship between maternal self-efficacy and parenting practices: implications for parent training. ChildCare, Health and Development, 31, 1, 65-73.

Simadi, F. ,2006, United Arab Emirates youths between modernity and traditionalism. International Journal of Sociology and Social Policy, 26(3/4), 172-184.

Simadi, F., Fatayer, J., \& Athamneh, S. ,2003, The Arabian family in the light of Minuchin's systematic theory: An analytical approach. Social Behavior and Personality: An international journal, 32(6), 467483.

Spirito, A., Stark, L. J., Gil, K. M., \& Tyc, V. L. ,1995, Coping with every day and disease-related stressors by chronically ill children and adolescents. Journal of the American Academy of Child and Adolescent Psychiatry, 22(3), 34-290.

Spoth, R. L., \& Conroy, S. M. ,1993, Survey of prevention-relevant beliefs and efforts to enhance parenting skills among rural parents. The Journal of Rural Health, 9(2), 227-239.

Wrikat, A., \& Simadi, F. ,2001, The Arabian modern man: A comparative study. International Journal of Sociology and Social Policy, 21(11/12) 41-45. 